\title{
Chickweed Tincture
}

National Cancer Institute

\section{Source}

National Cancer Institute. Chickweed Tincture. NCI Thesaurus. Code C87560.

A tincture made from the dried parts of Stellaria media, a widespread annual plant.

Chickweed tincture contains mucilage, saponins, silica, minerals, vitamins A, B, C and fatty acids. It may have expectorant and anti-septic actions. 